\title{
Response of the mesopause airglow to solar activity inferred from measurements at Zvenigorod, Russia
}

\author{
N. Pertsev and V. Perminov \\ A. M. Obukhov Institute of Atmospheric Physics, Pyzhevskiy per., 3, Moscow, 119017, Russia \\ Received: 14 December 2006 - Revised: 20 March 2007 - Accepted: 11 April 2007 - Published: 28 May 2008
}

\begin{abstract}
Ground-based spectrographical observations of infrared emissions of the mesopause region have been made at Zvenigorod Observatory (56 N, 37 E), located near Moscow, Russia, for 670 nights of 2000-2006. The characteristics of the hydroxyl and molecular oxygen $(865 \mathrm{~nm})$ airglow, heights of which correspond to 87 and $94 \mathrm{~km}$, are analyzed for finding their response to solar activity. The measured data exhibit a response to the $\mathrm{F}_{10.7}$ solar radio flux change, which is 30\%-40\%/100 sfu in intensities of the emissions and about $4.5 \mathrm{~K} / 100 \mathrm{sfu}$ in hydroxyl temperature. Seasonal variations of the airglow response to solar activity are observed. In winter it is more significant than in summer. Mechanisms that may provide an explanation of the solar influence on intensities of the emissions and temperature are considered. Radiative processes not involving atmospheric dynamics appear insufficient to explain the observed effect.
\end{abstract}

Keywords. Atmospheric composition and structure (Middle atmosphere - composition and chemistry; Airglow and aurora; Pressure, density and temperature)

\section{Introduction}

At present there is a great interest to investigations of the solar-terrestrial relations in the mesosphere and lower thermosphere (MLT). In comparison with the upper layers of the thermosphere, in the MLT region the response to solar activity was expected to be small and was left out of account in models of the middle atmosphere (CIRA, MSIS), although the first early researches gave evidence of the 11-year cycle in the hydroxyl airglow intensity (Shefov, 1973; Wiens and Weill, 1973) and mesopause temperature (Shefov, 1973). The following results of investigations of solar activity influence on the middle atmosphere are related to the works of

Correspondence to: N. Pertsev

(pertsev@mirea.ru)
Chanin et al. (1989), Hauchecorne et al. (1991) and Keckhut et al. (1995). Recently Beig et al. (2003) have drawn special attention to the importance of solar activity influence on the MLT region. A number of papers on this problem has been published (Burns et al., 2002; Gavrilyeva and Ammosov, 2002; Clemesha et al., 2005; Scheer et al., 2005; Beig, 2006; Golitsyn et al., 2006; Liu and Shepherd, 2006). They showed that the investigation of the solar signature in variations of the MLT emission characteristics require highprecision measurements. The results of all the above mentioned works also indicated differences in the solar effect at various geographic latitudes. All this encourages continuation of such research.

In this paper we present new mid-latitudinal airglow data, observed in 2000-2006, and concentrate our efforts on the analysis of solar influence upon them. The data provide characteristics of the hydroxyl and molecular oxygen Atmospheric system emissions, located near 87 and $94 \mathrm{~km}$ (i.e. in the region of the mesopause). In the discussion we pay attention to mechanisms providing the influence of solar activity on the airglow characteristics. Any comparison of our statistical results with results of similar investigations at other latitudes and with other techniques seems to be premature.

\section{Measurements and analyzed emission characteristics}

An infrared spectrograph equipped with a charge coupled device (CCD) was used to obtain data presented in this work. The detailed description of the instrument, spectrum, and its processing has been given by Semenov et al. (2002). The instrument allows us to measure the spectrum covering the wavelengths from 0.77 to $1.04 \mu \mathrm{m}$. This spectral range includes $\mathrm{OH}$ bands of sequences $\Delta v=3,4$ and 5 and the $(0-1)$ band of the $\mathrm{O}_{2}$ Atmospheric system. The instrument has a 600 grooves $/ \mathrm{mm}$ grating with a working area of $120 \times 95 \mathrm{~mm}$. Its field of view is 9 degrees. The CCD has $1024 \times 128$ pixels

Published by Copernicus Publications on behalf of the European Geosciences Union. 


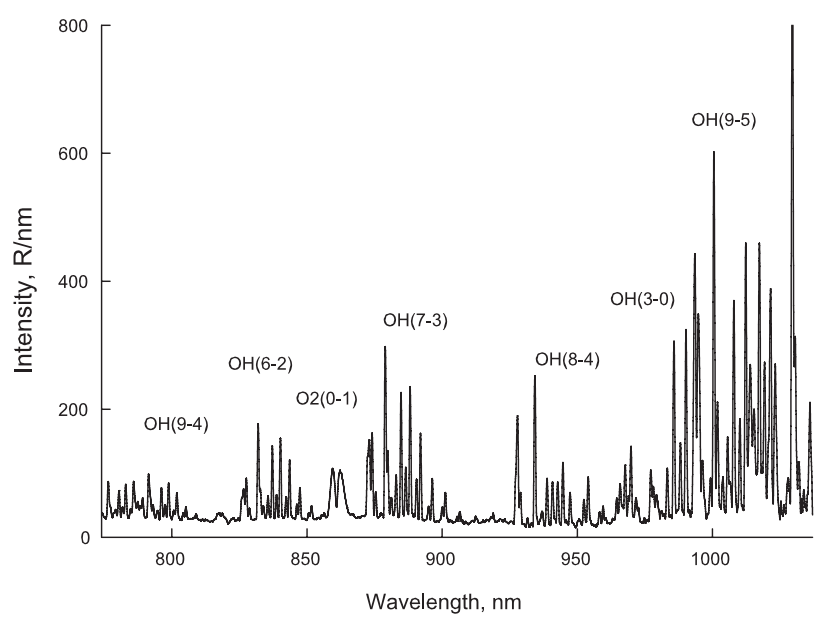

Fig. 1. Spectrum of the night airglow observed at Zvenigorod Observatory on 19 May 2001.

with a size of $26 \times 26 \mu \mathrm{m}$ and pixel quantum efficiency of up to 0.6 at $0.85 \mu \mathrm{m}$. It was cooled $\left(-50^{\circ} \mathrm{C}\right)$ to reduce its dark current. A spectrogram is acquired in $30 \mathrm{~s}$ with a resolution of about $0.3 \mathrm{~nm}$. In order to improve the signal-to-noise ratio for analyzing the spectra for temperature and band intensities, 20 spectrograms are summed. The spectrograms are also reduced to the zenithal conditions and are corrected for the spectral sensitivity of the instrument by absolute calibration (in Rayleigh units (R)) with a low radiation source, which in turn was calibrated by comparing with the spectrum of the star Capella ( $\alpha$ Aur). All these gave the intensity measurement error of lesser than $1 \%$. Figure 1 shows a typical spectrum observed at Zvenigorod Observatory on 19 May 2001 and corrected for spectral response of the instrument and its absolute calibration.

The airglow measurements were made at the Obukhov Institute of Atmospheric Physics Zvenigorod Observatory $(55.7 \mathrm{~N}, 36.8 \mathrm{E})$ in clear or weakly cloudy nights during 2000-2006. The measurements are centered at zenith angle $53^{\circ}$ and azimuth $22.6^{\circ}$ counted from North to West. The total number of nights of observations is 670 , distributed rather uniformly among the years and seasons. Data from all nights are utilized for the temperature analysis, but in the analysis of emission intensities only data of the 442 clear nights are used. The observation duration for a single night depended on the weather conditions, but was close to $12 \mathrm{~h}$ during the winter and only $1 \mathrm{~h}$ around midnight in the period of the summer solstice, when the minimum shadow height is about $100 \mathrm{~km}$. In order to maintain uniform sampling across the seasons, only data of the observations for midnight (from $23 \mathrm{~h} 30 \mathrm{~min}$ to $0 \mathrm{~h} 30 \mathrm{~min}$ local solar time) are analyzed below.

Although the instrument allowed us to measure simultaneously spectral features of the $\mathrm{OH}$ bands (3-0), (4-1), (5-1), $(6-2),(7-3),(8-4),(9-4)$ and (9-5), the behaviour of their in- tensities and response to solar activity was similar. Therefore for demonstration of results of the $\mathrm{OH}$ intensity and temperature analysis, the band (6-2) was chosen. It is necessary to note that in the earlier years (before 2000) emission measurements at Zvenigorod were carried out (Shefov et al., 2006). However, in the period 2000-2006 our observations give not only the hydroxyl intensity and temperature, but also the $\mathrm{O}_{2}$ (0-1) $865 \mathrm{~nm}$ Atmospheric band intensity and the ratio between intensities of the $\mathrm{OH}$ bands (7-3) and (9-4), being an indicator of the neutral density at the peak height of the hydroxyl emission (Pertsev et al., 1999; Shefov et al., 2006).

Intensities of hydroxyl band lines and the molecular oxygen (0-1) Atmospheric band were calculated by summing the intensities of matrix columns under the contours of the corresponding spectral features. The background continuum was determined by performing a cubic spline interpolation on the lowest intensities of matrix columns on the spectrograms. These calculated line intensities were corrected by atmospheric transmission coefficients given in (Espy and Hammond, 1995). Total intensities of hydroxyl bands, $I\left(V^{\prime} \rightarrow V^{\prime \prime}\right)$, were estimated by the expression

$$
\begin{aligned}
& I\left(V^{\prime} \rightarrow V^{\prime \prime}\right)= \\
& \quad \frac{I\left(V^{\prime}, J^{\prime} \rightarrow V^{\prime \prime}, J^{\prime \prime}\right) \cdot A\left(V^{\prime} \rightarrow V^{\prime \prime}\right) \cdot Q_{v^{\prime}}\left(T_{r}\right)}{A\left(V^{\prime}, J^{\prime} \rightarrow V^{\prime \prime}, J^{\prime \prime}\right) \cdot 2(2 J+1) \exp \left[-\frac{h c}{k} \cdot \frac{F\left(J^{\prime}\right)}{T_{r}}\right]}
\end{aligned}
$$

where $I\left(V^{\prime}, J^{\prime} \rightarrow V^{\prime \prime}, J^{\prime \prime}\right)$ is the intensity of the line P1(3), $A\left(V^{\prime} \rightarrow V^{\prime \prime}\right)$ and $A\left(V^{\prime}, J^{\prime} \rightarrow V^{\prime \prime}, J^{\prime \prime}\right)$ are the probabilities of vibrational and rotation-vibration transitions, which were adopted from the paper (Langhoff et al., 1986), $Q_{v^{\prime}}\left(T_{r}\right)$ is the rotational state function:

$$
\begin{aligned}
Q_{v^{\prime}}\left(T_{r}\right)= & \sum_{J^{\prime}} A\left(V^{\prime}, J^{\prime} \rightarrow V^{\prime}, J^{\prime \prime}\right) \cdot 2\left(2 J^{\prime}+1\right) \\
& \exp \left[-\frac{h c}{k} \frac{F\left(J^{\prime}\right)}{T_{r}}\right],
\end{aligned}
$$

$F\left(J^{\prime}\right)$ is the rotational term value (in $\mathrm{cm}^{-1}$ ), $T_{r}$ is the rotational temperature, which, supposing the Boltzmann distribution of populations over rotational levels, is determined by the regression equation (Turnbull and Lowe, 1983; Hecht et al., 1987, Shefov et al., 2006)

$\ln \left[\frac{I\left(V^{\prime}, J^{\prime} \rightarrow V^{\prime \prime}, J^{\prime \prime}\right)}{A\left(V^{\prime}, J^{\prime} \rightarrow V^{\prime \prime}, J^{\prime \prime}\right)}\right]=-\frac{h c}{k} \cdot \frac{F\left(J^{\prime}\right)}{T_{r}}+$ const

For the determination of the rotational temperature, the P1(2), P1(3) and P1(4) lines of the $\mathrm{OH}$ band (6-2) were used. Since the error of their measurements was low $(<1 \%)$, the accuracy in the calculation of the temperature was sufficiently high, $1-2 \mathrm{~K}$.

\section{Analysis}

Midnight mean data on the intensities of the $\mathrm{OH}$ band (6-2) and $\mathrm{O}_{2}$ Atmospheric band (0-1), the intensity ratio of the $\mathrm{OH}$ 
Table 1. Characteristics of seasonal variation harmonics.

\begin{tabular}{|c|c|c|c|c|c|c|c|}
\hline $\begin{array}{l}\text { Emission } \\
\text { characteristics }\end{array}$ & Mean & $\begin{array}{l}\text { Amplitude } \\
\text { of the } \\
\text { annual } \\
\text { harmonic }\end{array}$ & $\begin{array}{l}\text { Maximum } \\
\text { phase of } \\
\text { the annual } \\
\text { harmonic }\end{array}$ & $\begin{array}{l}\text { Amplitude } \\
\text { of the } \\
\text { semi- } \\
\text { annual } \\
\text { harmonic }\end{array}$ & $\begin{array}{l}1 \text { st maxi- } \\
\text { mum } \\
\text { phase of } \\
\text { the semi- } \\
\text { annual } \\
\text { harmonic }\end{array}$ & $\begin{array}{l}\text { Amplitude } \\
\text { of the } \\
\text { ter-annual } \\
\text { harmonic }\end{array}$ & $\begin{array}{l}\text { 1st maxi- } \\
\text { mum } \\
\text { phase of } \\
\text { the } \\
\text { ter-annual } \\
\text { harmonic }\end{array}$ \\
\hline$I_{O H(6-2)}$ & $\begin{array}{l}871 \pm 15^{*} \\
\mathrm{R}\end{array}$ & $\begin{array}{l}75 \pm 18 \\
\mathrm{R}\end{array}$ & $\begin{array}{l}275 \pm 20 \\
\text { day }\end{array}$ & $\begin{array}{l}23 \pm 21 \\
\mathrm{R}\end{array}$ & $\begin{array}{l}62 \pm 25 \\
\text { day }\end{array}$ & $\begin{array}{l}80 \pm 21 \\
\mathrm{R}\end{array}$ & $\begin{array}{l}63 \pm 4 \\
\text { day }\end{array}$ \\
\hline$I_{O 2(0-1)}$ & $\begin{array}{l}348 \pm 8 \\
\mathrm{R}\end{array}$ & $\begin{array}{l}101 \pm 11 \\
\mathrm{R}\end{array}$ & $\begin{array}{l}295 \pm 7 \\
\text { day }\end{array}$ & $\begin{array}{l}48 \pm 11 \\
\mathrm{R}\end{array}$ & $\begin{array}{l}54 \pm 7 \\
\text { day }\end{array}$ & $\begin{array}{l}33 \pm 11 \\
\mathrm{R}\end{array}$ & $\begin{array}{l}53 \pm 6 \\
\text { day }\end{array}$ \\
\hline$\frac{I_{\mathrm{OH}(7-3)}}{I_{\mathrm{OH}(9-4)}}$ & $4.10 \pm 0.02$ & $0.14 \pm 0.02$ & $\begin{array}{l}337 \pm 12 \\
\text { day }\end{array}$ & $0.17 \pm 0.03$ & $\begin{array}{l}154 \pm 23 \\
\text { day }\end{array}$ & $0.24 \pm 0.03$ & $\begin{array}{l}32 \pm 26 \\
\text { day }\end{array}$ \\
\hline$T_{r}$ & $\begin{array}{l}194.0 \pm 0.4 \\
\mathrm{~K}\end{array}$ & $\begin{array}{l}24.3 \pm 0.5 \\
\mathrm{~K}\end{array}$ & $\begin{array}{l}353 \pm 1 \\
\text { day }\end{array}$ & $\begin{array}{l}7.0 \pm 0.5 \\
\mathrm{~K}\end{array}$ & $\begin{array}{l}85 \pm 2 \\
\text { day }\end{array}$ & $\begin{array}{l}1.7 \pm 0.5 \\
\mathrm{~K}\end{array}$ & $\begin{array}{l}98 \pm 5 \\
\text { day }\end{array}$ \\
\hline
\end{tabular}

* Here and hereinafter the standard errors

Table 2. Slope coefficient of the regression line $T_{r}\left(\mathrm{~F}_{10.7}\right)$.

\begin{tabular}{llll}
\hline $\begin{array}{l}\text { Emission } \\
\text { characteristics }\end{array}$ & All data & Winter & Summer \\
\hline$I_{\mathrm{OH}(6-2)}$ & $2.1 \pm 0.3$ & $3.8 \pm 0.8$ & $1.7 \pm 0.3$ \\
& $\mathrm{R} \cdot \mathrm{sfu}^{-1}$ & $\mathrm{R} \cdot \mathrm{sfu}^{-1}$ & $\mathrm{R} \cdot \mathrm{sfu}^{-1}$ \\
$I_{\mathrm{O} 2(0-1)}$ & $1.1 \pm 0.2$ & $2.3 \pm 0.5$ & $-0.8 \pm 2.9$ \\
& $\mathrm{R} \cdot \mathrm{sfu}^{-1}$ & $\mathrm{R} \cdot \mathrm{sfu}^{-1}$ & $\mathrm{R} \cdot \mathrm{sfu}^{-1}$ \\
$I_{O H(7-3)}$ & $(2.2 \pm 0.4) \times 10^{-3}$ & $(1.5 \pm 0.8) \times 10^{-3}$ & $(2.8 \pm 1.3) \times 10^{-3}$ \\
$I_{O H(9-4)}$ & $\mathrm{sfu}-1$ & $\mathrm{sfu}$ & $\mathrm{sfu}$ \\
$T_{r}$ & $(4 \pm 1) \times 10^{-1}$ & $(7 \pm 2) \times 10^{-2}$ & $(2 \pm 2) \times 10^{-2}$ \\
& $\mathrm{~K} \cdot \mathrm{sfu}^{-1}$ & $\mathrm{~K} \cdot \mathrm{sfu}^{-1}$ & $\mathrm{~K} \cdot \mathrm{sfu}^{-1}$ \\
\hline
\end{tabular}

bands (7-3) to (9-4), and the hydroxyl rotational temperature for 2000-2006 are plotted in Fig. 2. Also this figure shows the Penticton daily solar radio flux $\mathrm{F}_{10.7}$, expressed in solar flux units (sfu). In spite of the fact that the observation period does not include all the 11-year solar cycle, it included both the solar activity maximum and its minimum. This allows us to investigate solar activity signatures in all the emission characteristics.

The data have been analyzed by regression methods: (1) linear fitting and (2) sinusoid fitting with a period of 11 years. Since the emission characteristics strongly vary during a year (Bakanas and Perminov, 2003; Perminov et al., 2004), the first three annual harmonics, mean for 2000-2006, were excluded beforehand from the data. The parameters that fit the data by a least-mean-squares method are given in Table 1 . The standard errors shown here and in other tables are mainly due to geophysical variability of temperature and intensity of the mesopause airglow. It is obvious from Fig. 2, that intensity and temperature may differ from night to night much stronger than it would be due to their measurement errors ( $1 \%$ for intensity, $1-2 \mathrm{~K}$ for temperature). The deseasonalized emission characteristic sets were analyzed by counting first all the data (not dependent on a season), and then separately those for November-January ("winter") and May-July ("summer"). The results obtained by the first and second methods of the regression analysis are shown in Table 2 and Table 3, respectively. Moreover, Table 3 shows the amplitudes of the solar cycle variation, determined from all data and separately from those for winter and summer. For a convenient comparison of the derived results the data from Table 3 were reduced to units analogous to those from Table 2 by dividing the amplitudes of the emission characteristics by the corresponding amplitudes of the solar cycle variation of $\mathrm{F}_{10.7}$ and are given in Table 4. As can be seen 
Table 3. Amplitude of the 11-year variation.

\begin{tabular}{llll}
\hline $\begin{array}{l}\text { Emission } \\
\text { characteristics }\end{array}$ & All data & Winter & Summer \\
\hline$I_{\mathrm{OH}(6-2)}$ & $168 \pm 20$ & $246 \pm 65$ & $156 \pm 33$ \\
& $\mathrm{R}$ & $\mathrm{R}$ & $\mathrm{R}$ \\
$I_{\mathrm{O} 2(0-1)}$ & $86 \pm 10$ & $140 \pm 40$ & $25 \pm 16$ \\
& $\mathrm{R}$ & $\mathrm{R}$ & $\mathrm{R}$ \\
$I_{\mathrm{OH}(7-3)}$ & $0.16 \pm 0.03$ & $0.09 \pm 0.06$ & $0.16 \pm 0.07$ \\
$I_{\mathrm{OH}(9-4)}$ & $2.6 \pm 0.4$ & $5.0 \pm 1.0$ & $1.0 \pm 1.0$ \\
$T_{r}$ & $\mathrm{~K}$ & $\mathrm{~K}$ & $\mathrm{~K}$ \\
$F_{10.7}$ & $53 \pm 1$ & $61 \pm 2$ & $42 \pm 2$ \\
& $\mathrm{sfu}$ & $\mathrm{sfu}$ & $\mathrm{sfu}$ \\
\hline
\end{tabular}

Table 4. Response of the emission characteristics to solar activity as the ratio of their 11-year variations.

\begin{tabular}{llll}
\hline $\begin{array}{l}\text { Emission } \\
\text { characteristics }\end{array}$ & All data & Winter & Summer \\
\hline$I_{\mathrm{OH}(6-2)}$ & $3.1 \pm 0.4$ & $4.0 \pm 1.0$ & $3.7 \pm 0.8$ \\
& $\mathrm{R} \cdot \mathrm{sfu}^{-1}$ & $\mathrm{R} \cdot \mathrm{sfu}^{-1}$ & $\mathrm{R} \cdot \mathrm{sfu}^{-1}$ \\
$I_{\mathrm{O} 2(0-1)}$ & $1.6 \pm 0.2$ & $2.3 \pm 0.7$ & $0.6 \pm 0.4$ \\
& $\mathrm{R} \cdot \mathrm{sfu}^{-1}$ & $\mathrm{R} \cdot \mathrm{sfu}^{-1}$ & $\mathrm{R} \cdot \mathrm{su}^{-1}$ \\
$I_{\mathrm{OH}(7-3)}$ & $(3.0 \pm 0.6) \times 10^{-3}$ & $(1.5 \pm 1.0) \times 10^{-3}$ & $(3.8 \pm 1.7) \times 10^{-3}$ \\
$I_{\mathrm{OH}(9-4)}$ & $\mathrm{sfu}^{-1}$ & $\mathrm{sfu}^{-1}$ & $\mathrm{sfu}-1$ \\
$T_{r}$ & $(4.9 \pm 0.8) \times 10^{-2}$ & $(8.2 \pm 1.6) \times 10^{-2}$ & $(2.4 \pm 2.4) \times 10^{-2}$ \\
& $\mathrm{~K} \cdot \mathrm{ffu}^{-1}$ & $\mathrm{~K} \cdot \mathrm{ffu}^{-1}$ & $\mathrm{~K} \cdot \mathrm{su}^{-1}$ \\
\hline
\end{tabular}

from the first columns of the Tables 2 and 4, all the emission characteristics show a positive response to solar activity. The changes of the hydroxyl and molecular oxygen emissions are most significant $(\sim(260 \mathrm{R}$ or $30 \%) / 100 \mathrm{sfu}$ and $\sim(135 \mathrm{R}$ or $39 \%$ )/100 sfu, respectively; percents are given of the mean intensities (see the first column of Table 1)). The responses of the hydroxyl temperature and intensity ratio of the hydroxyl bands (7-3) and (9-4) are $4 \div 5 \mathrm{~K} / 100$ sfu and $\sim 0.26 / 100$ sfu. All responses show a dependence on the season. In winter the response magnitudes for the intensities and temperature are greater than the summer ones. So, the hydroxyl temperature response in winter is $7 \div 8 \mathrm{~K} / 100 \mathrm{sfu}$, and in summer it, with account of its error, at $(\sim 2 \pm 2 \mathrm{~K} / 100 \mathrm{sfu})$ is rather negligible. The same situation applies to the intensity of the molecular oxygen emission: $\sim 230 \mathrm{R} / 100 \mathrm{sfu}$ in winter and $-80 \div+60 \mathrm{R} / 100 \mathrm{sfu}$ in summer. The seasonal difference of the response of the hydroxyl emission intensity to solar activity is seen only from the linear regression analysis (see Table 2). The opposite picture is seen for the intensity ratio of the hydroxyl emission bands (7-3) to (9-4). Its sum- mer response to solar activity can be greater than the winter one by more than two times. Taking into account that the ratio between intensities of the $\mathrm{OH}$ emissions from different vibrational levels changes together with neutral density at the emission peak height (Pertsev et al., 1999; Shefov et al., 2006), we can suppose that this density grows (especially, in summer) with increasing solar activity. However, comparing the magnitudes of the seasonal variations and solar activity responses (both in winter and summer) of the intensity ratio (see Tables 1,2 and 4) we should note that the change of the density at the peak height of the hydroxyl emission layer is negligible.

The seasonal dependence of the emission characteristics on solar activity may be expressed as a response in parameters of their seasonal variations to solar flux $\mathrm{F}_{10.7}$. It is seen from Fig. 2 that seasonal variations are observed in the hydroxyl temperature. We inferred the first three seasonal harmonics of temperature by a least-mean-squares fit for each year of 2000-2005. The harmonic parameters are given in Table 5. The annual mean temperature for 5 years fell from 


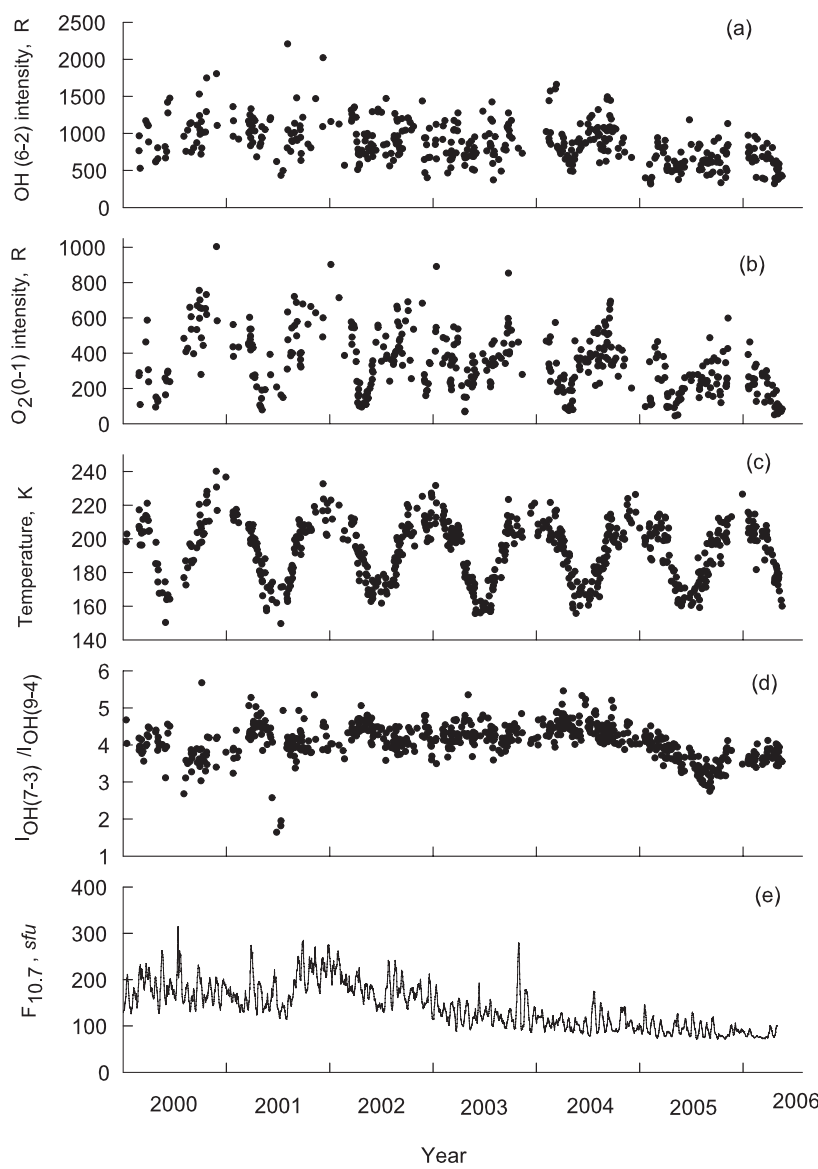

Fig. 2. Midnight data on intensities of the $\mathrm{OH}$ band (6-2) (a) and $\mathrm{O}_{2}$ Atmospheric band (0-1), hydroxyl temperature (b), ratio of the (7-3) and (9-4) $\mathrm{OH}$ band intensities $\left(\mathrm{I}_{\mathrm{OH}(7-3)} / \mathrm{I}_{\mathrm{OH}(9-4)}\right)$ and Penticton solar radio flux $\left(\mathrm{F}_{10.7}\right)$.

198 to $191 \mathrm{~K}$. The amplitude of the annual harmonic also decreased from 27 to $21 \mathrm{~K}$ for the same period. The amplitudes of other harmonics do not show the same tendency. It can be concluded from the inter-annual behaviour of the mean temperature and its annual amplitude that the greatest response to solar activity is in the winter hydroxyl temperature. This is illustrated in Fig. 3, in which the annual variations are reconstructed on the base of the parameters from Table 5 .

Nowadays a number of investigations of a response of the airglow characteristics to solar activity has been made (Burns et al., 2002; Gavrilyeva and Ammosov, 2002; Clemesha et al., 2005; Scheer et al., 2005; Golitsyn et al., 2006; Shefov et al., 2006). These works showed the response of the mean annual hydroxyl temperature to solar activity from $\sim 1 \mathrm{~K} / 100$ sfu (Scheer et al., 2005) to $\sim 11 \mathrm{~K} / 100$ sfu (Clemesha et al., 2005). The results of the analysis presented here give $4 \div 5 \mathrm{~K} / 100 \mathrm{sfu}$. However, it is necessary to draw attention to that the results of the investigations relate to different latitudes, and in the future it requires an additional research. Probably, the response of the airglow intensity to solar ac-

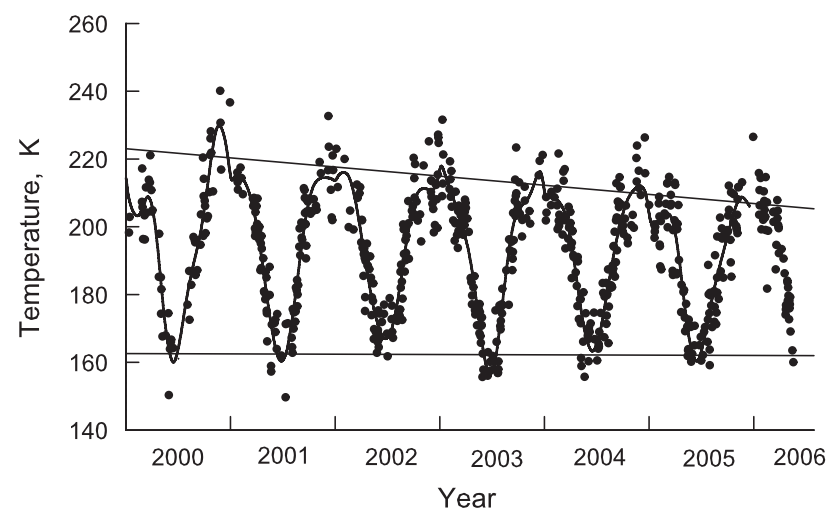

Fig. 3. Hydroxyl midnight temperature (dotes), reconstructed annual variations (curve) and regression lines, derived on the base of data for the winter solstice (upper line) and summer solstice (lower line).

tivity also depends on the latitude. So, in opposite to our measurements, at the latitude $32 \mathrm{~S}$ (Scheer et al., 2005) the airglow intensity response is insignificant.

Least of all the seasonal character of the airglow response to solar activity was investigated. Our work confirms the existence of this effect in the hydroxyl temperature (Golitsyn et al., 2006; Shefov et al., 2006) and finds the similar effect in intensities of the mesopause airglow emissions.

\section{Discussion on mechanisms of solar activity influence}

The key role of atomic oxygen as a mediator between solar activity and the airglow intensity is well-known (Scheer et al., 2005; Shefov et al., 2006). The found here significant response of the hydroxyl and molecular oxygen emission intensities to solar activity seems to be implemented through the relevant growth of atomic oxygen at the heights of the lower thermosphere and mesopause $(80-100 \mathrm{~km})$ due to dissociation of molecular oxygen in the Schumann-Runge spectral absorption region and the dependence of this process on the level of solar activity (Brasseur and Solomon, 1984). Photochemical models of the airglow (see, e.g., Greer et al., 1981; Makhlouf et al., 1995; Yee et al., 1997; Shefov et al., 2006) provide the following expressions in the first approximation for the volume emission rates (VER) of the $\mathrm{OH}$ and $\mathrm{O}_{2} \mathrm{At}$ mospheric bands:

$\operatorname{VER}(\mathrm{OH}) \sim n^{2} \cdot[\mathrm{O}]$,

$\operatorname{VER}\left(\mathrm{O}_{2}\right) \sim n \cdot[\mathrm{O}]^{2}$

where $n$ and $[\mathrm{O}]$ are the total concentration (number density) and atomic oxygen one, respectively. As stated in Sect. 3 the total density at the height of the hydroxyl emission layer shows little change with solar activity. A similar assumption for the molecular oxygen emission layer is under question. 
Table 5. Parameters of seasonal variations of hydroxyl temperature.

\begin{tabular}{llllllll}
\hline Year & $\begin{array}{l}\text { Annual mean, } \\
\mathrm{K}\end{array}$ & $\begin{array}{l}\text { Annual } \\
\text { amplitude, } \\
\mathrm{K}\end{array}$ & $\begin{array}{l}\text { Maximum } \\
\text { phase of } \\
\text { annual } \\
\text { harmonic, } \\
\text { day }\end{array}$ & $\begin{array}{l}\text { Semiannual } \\
\text { amplitude, } \\
\mathrm{K}\end{array}$ & $\begin{array}{l}\text { 1st maximum } \\
\text { phase of } \\
\text { semi-annual } \\
\text { harmonic, } \\
\text { day }\end{array}$ & $\begin{array}{l}\text { Ter-annual } \\
\text { amplitude, } \\
\mathrm{K}\end{array}$ & $\begin{array}{l}\text { 1st maximum } \\
\text { phase of } \\
\text { ter-annual } \\
\text { harmonic, } \\
\text { day }\end{array}$ \\
\hline 2000 & $197.6 \pm 1.3$ & $27.1 \pm 2.1$ & $350 \pm 3$ & $8.6 \pm 1.9$ & $101 \pm 5$ & $7.4 \pm 1.8$ & $90 \pm 5$ \\
2001 & $195.7 \pm 0.8$ & $26.8 \pm 1.1$ & $358 \pm 2$ & $8.4 \pm 1.0$ & $85 \pm 4$ & $0.7 \pm 1.0$ & $13 \pm 30$ \\
2002 & $196.2 \pm 0.8$ & $23.8 \pm 1.2$ & $357 \pm 3$ & $6.7 \pm 1.0$ & $77 \pm 6$ & $1.5 \pm 1.1$ & $34 \pm 15$ \\
2003 & $193.9 \pm 0.7$ & $26.6 \pm 1.1$ & $354 \pm 2$ & $7.2 \pm 1.0$ & $79 \pm 4$ & $4.0 \pm 1.0$ & $120 \pm 4$ \\
2004 & $193.8 \pm 0.7$ & $22.8 \pm 1.1$ & $351 \pm 2$ & $7.0 \pm 1.0$ & $78 \pm 4$ & $1.3 \pm 0.9$ & $88 \pm 15$ \\
2005 & $190.5 \pm 0.9$ & $21.0 \pm 1.6$ & $355 \pm 3$ & $7.5 \pm 1.0$ & $83 \pm 4$ & $3.7 \pm 1.1$ & $86 \pm 7$ \\
\hline
\end{tabular}

Nevertheless, in the first approximation the intensity of the $\mathrm{O}_{2}$ emission is governed only by the product of $[\mathrm{O}](n)$ independently from the variable $n(z)$ :

$$
\begin{aligned}
I\left(\mathrm{O}_{2}\right) \sim \int_{0}^{\infty} n \cdot[\mathrm{O}]^{2} d z & =\int_{n \max }^{0} \frac{[\mathrm{O}]^{2}}{d \ln n / d z} d n \\
& =\int_{0}^{n \max } H \cdot[\mathrm{O}]^{2} d n \\
& \approx H^{*} \cdot \int_{0}^{n \max }[\mathrm{O}]^{2} d n
\end{aligned}
$$

where $I\left(\mathrm{O}_{2}\right)$ is the integrated intensity of the molecular oxygen emission, $z$ is the height. Here we suppose that the density scale height $H=(-d \ln n / d z)^{-1}$ varies more slowly than $[\mathrm{O}]^{2}$ in the vicinity of the emission layer and, hence, may be substituted by its mean value $H^{*}$ weighted over the layer. This value is approximately proportional to temperature. From independent measurements of temperature and intensity of the $\mathrm{O}_{2}$ emission (Scheer et al., 2005) it is clear that temperature is less variable than the intensity. This means that variations of the molecular oxygen emission (as well as the hydroxyl one) are caused mainly by the change of [O] versus $n$. Thus, the changes of the $\mathrm{OH}$ and $\mathrm{O}_{2}$ emission intensities with solar activity imply a corresponding change of atomic oxygen with solar activity at the heights $80-100 \mathrm{~km}$.

The causes of solar activity influence on hydroxyl temperature are not as clear as on the airglow intensity. The first question that arises is whether the observed hydroxyl temperature change with solar activity may be caused by a vertical shift of the $\mathrm{OH}$ emission layer to warmer or cooler region. To answer this question, it is worthwhile to compare temperature and neutral density at the height of the hydroxyl emission during a solar cycle (see Tables 2 and 4), supposing that variations of this density are caused by a vertical shift of the hydroxyl emission layer (Pertsev et al., 1999). However, the hydroxyl temperature difference (up to $8 \mathrm{~K}$ in winter) between the maximum and minimum periods of solar activity is not accompanied by any significant difference in the density. Recently Liu and Shepherd (2006) showed from WINDII/UARS observations that in the latitudinal region $40 \mathrm{~S}-40 \mathrm{~N}$ the height response of the hydroxyl emission layer to solar activity is about $1 \mathrm{~km} / 100 \mathrm{sfu}$. Considering the current atmospheric models (e.g. NRLMSISE-00 (Picone et al., 2002)) one would find that such a change of the $\mathrm{OH}$ emission height could cause a change of not more than $2 \mathrm{~K}$ in hydroxyl temperature. Thus, the response of hydroxyl temperature to solar activity is not primarily caused by a change of the $\mathrm{OH}$ emission layer height.

Processes connecting the changes in hydroxyl temperature with solar activity may be different: (1) carbon dioxide cooling variation, (2) direct solar ultra-violet (UV) heating and thermoconductive heating in the vicinity of the hydroxyl emission layer, (3) dynamical processes such as the change of tidal amplitudes and/or phases, the adiabatic change of temperature due to vertical advection, heating/cooling through enhanced/suppressed turbulence and hydrodynamic wave absorption or through a change of turbulent heat flux. The first process, cooling by the $\mathrm{CO}_{2} 15-\mu \mathrm{m}$ emission above $80 \mathrm{~km}$, strongly depends on the concentration of atomic oxygen and the dissociation of carbon dioxide in the SchumannRunge continuum and the Ly- $\alpha$ line, which change with solar activity (Brasseur and Solomon, 1984). Atomic oxygen plays the key role in the translation of kinetic energy to the excitation of the $v_{2}$ vibrational mode of $\mathrm{CO}_{2}$ in the lower thermosphere (Khvorostovskaya et al., 2002). Thus, an increase of solar activity must cause, on one hand, a $\mathrm{CO}_{2}$ decrease due to intensified dissociation and a consequent heating effect (it must be more effective in summer, when there is nearly continuous illumination in the MLT at $56 \mathrm{~N}$ ). On the other hand, the growth of solar activity must cause an increase of vibration-translation changes due to the growth of atomic oxygen number density and, hence, intensification of the cooling. It is necessary to note that according to the atomic oxygen empirical model of Shefov et al. (2006), an 
increase of atomic oxygen concentration occurs near the $\mathrm{OH}$ emission layer in the October-November period. At this time the oxygen atom number density at $87 \mathrm{~km}$ would reach unusually high values, $\sim 5 \times 10^{11} \mathrm{~cm}^{-3}$ and $\sim 8 \times 10^{11} \mathrm{~cm}^{-3}$ at solar activity minimum and maximum, respectively. These speculations make us expect a stronger direct correlation of temperature with solar activity in summer and the countercorrelation in October-November, that is contrary to the observed picture (see Fig. 4). Here as in Fig. 3 the seasonal character of the temperature response to the gradually decreasing solar activity is clear. As can be seen from this figure the regression line for the June-July temperatures (grey circles) has small slope, and that for the October-November ones (black circles) has a larger slope (i.e. strong response of temperature to solar activity). Hence, $\mathrm{CO}_{2}$ cooling does not seem to be the real intermediate between solar activity and temperature. Similar ideas make us neglect the direct UVsolar heating of the hydroxyl emission layer heights and the thermoconductive heating from above. For these processes we should expect the strongest effect in summer.

Thus, the most probable mechanisms connecting temperature at the height of the hydroxyl emission layer with solar activity are dynamic processes and their dependence on solar activity. A solar effect is found in the long-term observations of the horizontal components of wind in the upper mesosphere and lower thermosphere (Fahrutdinova et al., 2006). The horizontal wind is a filter for the propagation of hydrodynamic waves from the lower atmosphere (e.g. Hines, 1974). Hence, its variations due to solar activity changes must cause changes in the propagation and dissipation of the waves and, as a consequence, in turbulence. In future, we will investigate changes of characteristics of the tides and gravity wave activity during a solar cycle.

\section{Conclusion}

The study of the response of the emission characteristics near the mesopause to solar activity has been carried out on the data of the spectrographic measurements at Zvenigorod Observatory. In spite of the fact that the observations for 20002006 do not cover a full solar cycle, dependence of the intensity of the hydroxyl and molecular oxygen (at $865 \mathrm{~nm}$ ) airglow and the temperature at $\sim 87 \mathrm{~km}$ on solar activity is found. The data show a positive correlation of airglow intensity and temperature with the solar radio flux index $\mathrm{F}_{10.7}$.

The main solar cycle features seen in the airglow characteristics are as follows.

1. The intensity responses of hydroxyl and molecular oxygen emissions to solar activity are approximately $30 \% / 100$ sfu and 40\%/100 sfu, respectively. The corresponding response for hydroxyl temperature is about $4.5 \mathrm{~K} / 100 \mathrm{sfu}$.

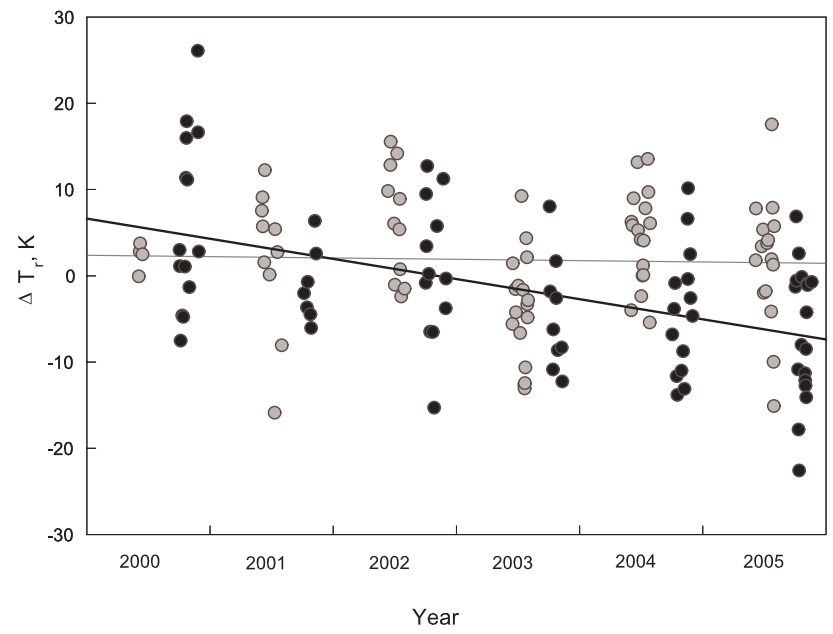

Fig. 4. Deviations $\left(\Delta \mathrm{T}_{r}\right)$ of the midnight hydroxyl temperature from the standard annual variations, presented in Table 1 , and regression lines for the periods of June-July (grey circles and line) and October-November (black circles and line).

2. Although the summer hydroxyl temperature does not show significant dependence on solar activity, the winter dependence is strong, $\sim 8 \mathrm{~K} / 100 \mathrm{sfu}$. This confirms previous reports by Golitsyn et al. (2006) and Shefov et al. (2006). The same character of the response to solar activity is seen in the molecular oxygen emission intensity and, to a lesser degree, in the hydroxyl emission intensity.

3. We believe that the discussion of mechanisms of the solar activity influence on the hydroxyl temperature requires the investigation of dynamic processes, which are responsible for the energy and composition redistribution at the heights $80-100 \mathrm{~km}$. In future, we will extend our investigation to the behaviour of gravity waves, tides, and planetary waves during a solar cycle.

Acknowledgements. The work was conducted under the support of Russian foundation for basic researches, grant 06-05-64856. The authors are thankful to N. N. Shefov, A. I. Semenov, R. Wiens and the anonymous referee for their useful comments and improvement of the paper text.

Topical Editor U.-P. Hoppe thanks R. Wiens and another referee for their help in evaluating this paper.

\section{References}

Bakanas, V. V. and Perminov, V. I.: Some features in the seasonal behavior of the hydroxyl emission characteristics in the upper atmosphere, Geomag. Aeron., 43(3), 363-369, 2003.

Bakanas, V. V., Perminov, V. I., and Semenov, A. I.: Seasonal variations of emission characteristics of the mesopause hydroxyl with different vibrational excitation, Adv. Space Res., 32, 765-770, 2003. 
Beig, G., Keckhut, P., Lowe, R. P., Roble, R., Mlynczak, M. G., Scheer, J., Fomichev, V., Offermann, D., French, W. J. R., Shepherd, M. G., Semenov, A. I., Remsberg, E., She, C. Y., Luebken, F. J., Bremer, J., Clemesha, B. R., Stegman, J., Sigernes, F., and Fodnavis, S.: Review of mesospheric temperature trends, Rev. Geophys., 41, 1015, doi:10.1029/2002RG000121, 2003.

Beig, G.: Trends in the mesopause region temperature and our present understanding - an update, Phys. Chem. Earth, 31, 3-9, 2006.

Brasseur, G. and Solomon, S.: Aeronomy of the Middle Atmosphere, D. Reidel Publishing Company, Dordrecht, Holland, 1984.

Burns, G. B., French, W. J. R., Greet, P. A., Phillips, F. A., Williams, P. F. B., Finlayson, K., and Klich, G.: Seasonal variations and inter-year trends in 7 years of hydroxyl airglow rotational temperatures at Davis station $\left(69^{\circ} \mathrm{S}, 78^{\circ} \mathrm{E}\right)$, Antarctica, J. Atmos. Sol. Terr. Phys., 64, 1167-1174, 2002.

Chanin, M.-L., Keckhut, P., Hauchecorne, A., and Labitzke, K.: The solar activity - Q.B.O. effect in the lower thermosphere, Ann. Geophys., 7, 463-470, 1989,

http://www.ann-geophys.net/7/463/1989/.

Clemesha, B., Takahashi, H., Simonich, D., Gobbi, D., and Batista, P.: Experimental evidence for solar cycle and long-term change in the low-latitude MLT region, J. Atmos. Sol. Terr. Phys., 67, 191-196, 2005.

Espy, P. J. and Hammond, M. R.: Atmospheric transmission coefficients for hydroxyl rotational lines used in rotational temperature determinations, J. Quant. Spectrosc. Radiat. Trans., 54, 879-889, 1995.

Fahrutdinova, A., Elkin, A., and Guryanov, V.: Height variability of solar effects on dynamical processes of middle atmosphere, Adv. Space Res., 37, 1589-1596, 2006.

Gavrilyeva, G. A. and Ammosov, P. P.: Near-mesopause temperatures registered over Yakutia, J. Atmos. Sol. Terr. Phys., 64, 985990, 2002.

Golitsyn, G. S., Semenov, A. I., Shefov, N. N., and Khomich, V. Yu.: The response of middle-latitudinal atmospheric temperature on the solar activity during various seasons, Phys. Chem. Earth, 31, 10-15, 2006.

Greer, R. G. H., Llewellyn, E. J., Solheim, B. H., and Witt, G.: The excitation of $\mathrm{O}_{2}\left(\mathrm{~b}^{1} \Sigma_{g}^{+}\right)$in the nightglow, Planet. Space Sci., 29, 383-389, 1981.

Hauchecorne, A., Chanin, M.-L., and Keckhut, P.: Climatology and trends of the middle atmospheric temperature $(33-87 \mathrm{~km})$ as seen by Rayleigh lidar over the south of France, J. Geophys. Res., 96, 15 297-15 309, 1991.

Hecht, J. H., Walterscheid, R. L., Sivjee, G. G., Christensen, A. B., and Pranke, J. B.: Observations of wave-driven fluctuations of $\mathrm{OH}$ nightglow emission from Sondre Stromfjord, Greenland, J. Geophys. Res., 92, 6091-6099, 1987.

Hines, C. O.: The upper atmosphere in motion, American Geophysical Union, 1974.

Keckhut, P., Hauchecorne, A., and Chanin, M.-L.: Midlatitude long-term variability of the middle atmosphere: trends and cyclic and episodic changes, J. Geophys. Res., 100, 18 887-18 897, 1995.
Khvorostovskaya, L. E., Potekhin, I. Yu., Shved, G. M., Ogibalov, V. P., and Uzyukova, T. V.: Measurement of the rate constant for quenching $\mathrm{CO}_{2}\left(01^{1} 0\right)$ by atomic oxygen at low temperatures: reassessment of the rate of cooling by the $\mathrm{CO}_{2}$ emission in the lower thermosphere, Izvestiya, Atmos. Oceanic Phys., 38, 613624, 2002.

Langhoff, S. R., Werner, H.-J., and Rosmus, P.: Theoretical transition probabilities for the OH Meinel system, J. Mol. Spectr., 118, 507-529, 1986.

Liu, G. and Shepherd, G. G.: An empirical model for the altitude of the OH nightglow emission, Geophys. Res. Lett., 33, L09805, doi:10.1029/2005GL025297, 2006.

Makhlouf, U. B., Picard, R. H., and Winick, J. R.: Photochemicaldynamical modeling of the measured response of airglow to gravity waves, J. Geophys. Res., 100, 11 289-11 311, 1995.

Perminov, V. I., Semenov, A. I., Bakanas, V. V., Zheleznov, Yu. A., and Khomich, V. Yu.: Regular variations in the (0-1) band intensity of the oxygen emission Atmospheric system, Geomag. Aeron., 44, 498-501, 2004.

Pertsev, N. N., Perminov, V. I., Lowe, R. P., and DeSerranno, R.: Effect of vertical motion of the hydroxyl nightglow layer on the observed variation of rotational temperature, Int. J. Geomagnetism and Aeronomy, 1(3), 259-265, 1999.

Picone, J. M., Hedin, A. E., Drob, D. P., and Aikin, A. C.: NRLMSISE-00 empirical model of the atmosphere: Statistical comparisons and scientific issues, J. Geophys. Res., 107, 1468, doi:10.1029/2002JA009430, 2002.

Scheer, J., Reisin, E. R., and Mandrini, C. H.: Solar activity signatures in mesopause region temperatures and atomic oxygen related airglow brightness at El Leoncito, Argentina, J. Atmos. Sol. Terr. Phys., 67, 145-154, 2005.

Semenov, A. I., Bakanas, V. V., Perminov, V. I., Zheleznov, Ya. A., and Khomich, V. Yu.: The near infrared spectrum of the emission of the nighttime upper atmosphere, Geomagn. Aeron., 42, 390397, 2002.

Shefov, N. N.: Behaviour of the hydroxyl emission during solar cycle, seasons and geomagnetic disturbances (in Russian), in: Aurorae and Airglow, Articles Collection N 20, Nauka, Moscow, 23-39, 1973.

Shefov, N. N., Semenov, A. I., and Khomich, V. Yu.: Airglow as indicator of the upper atmospheric structure and dynamics (in Russian), Geos, Moscow, 741 pp., 2006.

Turnbull, D. N. and Lowe, R. P.: Vibrational population distribution in the hydroxyl night airglow, Can. J. Phys., 61, 244-250, 1983.

Wiens, R. H. and Weill, G.: Diurnal, annual and solar cycle variations of hydroxyl and sodium nightglow intensities in the Europe-Africa sector, Planet. Space Science, 21, 1011-1027, 1973.

Yee, J.-H., Crowley, G., Roble, R. G., Skinner, W. R., Burrage, M. D., and Hays, P. B.: Global simulations and observations of $\mathrm{O}\left({ }^{1} \mathrm{~S}\right), \mathrm{O}_{2}\left({ }^{1} \Sigma\right)$ and $\mathrm{OH}$ mesospheric nightglow emissions, J. Geophys. Res., 102, 19949-19968, 1997. 